\title{
Integrative omics analysis on phytohormones involved in oil palm seed germination
}

Yong Wang ${ }^{1 *+} \mathbb{D}$, Yin Min Htwe ${ }^{1,2 \dagger}$, Jing $\mathrm{Li}^{1}$, Peng Shi ${ }^{1}$, Dapeng Zhang ${ }^{1}$, Zhihao Zhao ${ }^{1}$ and Leonard Osayande Ihase ${ }^{3}$

\begin{abstract}
Background: Heat treatment is widely used to break dormancy for seed germination and phytohormones could be deeply involved. However, effect of heat treatment on phytohormone related genes/proteins/metabolites and possible relationship with dormancy release remains unclear in oil palm. In this study, oil palm seeds were heat-treated at $39^{\circ} \mathrm{C}$ for 60 days according to the method for commercial production. The embryos of seeds during heat treatment $(0 \mathrm{~d}, 15$ $\mathrm{d}, 30 \mathrm{~d}, 45 \mathrm{~d}$ and $60 \mathrm{~d}$ ) and of germinated seeds (70 d and $75 \mathrm{~d}$ ) were selected to discover the mechanisms involved in oil palm seed germination. RNA-seq and iTRAQ were applied to investigate DEGs and DEPs related to seed germination; GPCR and western blot were used as validation accordingly; endogenous phytohormones were determined by LC-MS/MS and exogenous phytohormones were also applied to validate their effects on seed germination.
\end{abstract}

Results: RNA-seq results showed that plant hormone signal transduction was one of the most important pathways and eight phytohormones involved, while six of them (ABA, GA, ET, CTK, IAA and JA) were also identified by iTRAQ. Both RNA-seq and iTRAQ results showed that the expression of ABA decreased after heat treatment, which was further validated by qPCR and western blot. Furthermore, changes in endogenous phytohormones showed that ABA decreased rapidly to about $9 \%$ of the control at $30 \mathrm{~d}$ and then stayed at very low levels until germination; GA and CTK increased while IAA was not affected by heat treatment. Besides, exogenous ABA treatments $(10,100,1000 \mathrm{mg} / \mathrm{L})$ showed that the germination rate decreased to 63,42 and $16 \%$ of the control, respectively, suggesting that ABA suppress seed germination and the inhibition effect increase with higher concentration; while the germination rates of exogenous GA and IAA treatments barely changed among different concentrations.

Conclusions: Phytohormones are deeply involved in oil palm seed germination and ABA acts as an inhibitor. Heat treatment can eliminate endogenous ABA and break dormancy, while GA and CTK may also involve in dormancy release. At least 30 days of heat treatment might be necessary. This study provided informative perspectives on oil palm seed germination, which could be also applicable in other palm species.

Keywords: Dormancy, Hormone, Inhibitor, iTRAQ, RNA-seq, Western blot

\footnotetext{
*Correspondence: Elaeis@catas.cn

${ }^{+}$Yong Wang and Yin Min Htwe contributed equally to this work.

'Hainan Key Laboratory of Tropical Oil Crops Biology, Coconut Research

Institute, Chinese Academy of Tropical Agricultural Sciences, Wenchang

571339, People's Republic of China

Full list of author information is available at the end of the article
}

(c) The Author(s). 2019 Open Access This article is distributed under the terms of the Creative Commons Attribution 4.0 International License (http://creativecommons.org/licenses/by/4.0/), which permits unrestricted use, distribution, and reproduction in any medium, provided you give appropriate credit to the original author(s) and the source, provide a link to the Creative Commons license, and indicate if changes were made. The Creative Commons Public Domain Dedication waiver (http://creativecommons.org/publicdomain/zero/1.0/) applies to the data made available in this article, unless otherwise stated. 


\section{Background}

Oil palm (Elaeis guineensis Jacq.) is one of the largest sources of vegetable oils, which contributes $33 \%$ of vegetable oil and $45 \%$ of edible oil production throughout the world $[1,2]$. With the increasing population, sustainable development of this industry is necessary to meet the increasing consumption of palm oil globally [3].

Seed germination is crucial to seedling propagation and agricultural production [4-6]. Oil palm seeds are difficult to germinate because of seed dormancy and the germination is very slow under natural conditions. Heat treatment is an effective method to break dormancy for rapid germination [7-10].

Previous studies showed that the key players in the process of seed germination are plant hormones and the major phytohormones are abscisic acid (ABA) and gibberellin (GA), which have antagonistic effects on seed germination [11]. ABA is the key hormone in maintaining seed dormancy while GA is known to counteract ABA effects, thus promoting seed germination [12, 13]. ABA accumulates to initiate seed dormancy during seed maturation; ABA is downregulated while GA is up-regulated before the onset of germination process. In addition, several other phytohormones including auxin (Aux), ethylene (ET), brassinosteroid (BR), cytokinin (CTK) and jasmonic acid (JA) are also involved in seed dormancy and germination processes [14].

Several studies have reported the effect of phytohormones on seed germination [13-17]. Furthermore, changes in hormone concentrations during dormancy release of oil palm seeds have been reported [18]. Nevertheless, previous studies on the effect of heat treatment mainly focus on changes in seed germination rate and endogenous phytohormones, related mechanism remains unclear and further systematic research through integrative omics analysis is required.

The oil palm genome $(1.8 \mathrm{~Gb})$ was released by the Malaysian Palm Oil Board [2] and was then widely used as the reference genome. Transcriptomic analysis has been immensely useful in discovering mRNA expression levels [19], and proteomic analysis can identify gene expression changes at protein level [20]. However, analyzing transcriptome or proteome separately may not be very informative, while integrative transcriptomic-proteomic analysis could provide complementary information [20]. For example, the integrative analysis of the transcriptome and proteome improves the understanding of fruit ripening in citrus [21], the integration of the proteome and transcriptome reveals multiple levels of gene regulation in the rice $\mathrm{dl} 2$ mutant [22]. Therefore, based on available oil palm genome in public database, integrative omics analysis may help to reveal more comprehensive information and related mechanism in the oil palm seed germination process. While to our knowledge, the integrative analysis of transcriptomics and proteomics in oil palm seed germination has not been reported previously.

In this study, Integrative analysis of RNA-seq and iTRAQ were applied to investigate DEGs and DEPs related to oil palm seed germination. The expression profiles of phytohormone related DEGs/DEPs at different developmental stages were validated by qPCR and western blot analysis, respectively. The changes in the endogenous phytohormones during seed germination were determined by LC-MS/MS analysis. Furthermore, exogenous phytohormones were applied to validate their effects on seed germination. As seed germination is very important for propagation, the present study may provide new perspective on oil palm seed germination, which could be useful for oil palm seedling propagation and may be also applicable in other palm species.

\section{Results}

Assessment digital gene expression (DGE) sequencing

Nine DGE libraries were generated from non-germinated $(0 \mathrm{~d})$ and germinated embryos (70 d and $75 \mathrm{~d}$ ), with three biological replicates. Each library produced over 12 million high quality clean reads, and the percentage was above 99\% among the raw reads (Additional file 1: Figure S1). Among the clean reads, the number of sequences that could be mapped to reference genome ranged from 10 to 11 million ( $>85 \%)$. The percentage of unique match was $>82 \%$ and the percentage of multi-position mapped reads was $<3 \%$ (Additional file 2: Table S1).

The expression level of each gene is determined by the fragments per kilobase of transcripts per million fragments mapped (FPKM) method. The results of gene expression and related information for all samples were given in Additional file 3: Table S2. The correlation of gene expression level among biological replicates is a key criterion to test whether the experiments are reliable and whether the samples chosen are reasonable. If one sample is highly similar with another one, the correlation value between them is very close to 1 . In this analysis, the correlation value between each two samples was calculated based on FPKM result. All the correlation values are $\geq 0.99$, indicating a good correlation between replicates (Additional file 4: Table S3).

\section{Differentially expressed genes (DEGs) and proteins (DEPs) analysis}

The differentially expressed genes (DEGs) and differentially expressed proteins (DEPs) were identified in (a) between $0 \mathrm{~d}$ and 70d; (b) between $0 \mathrm{~d}$ and $75 \mathrm{~d}$. Totally 8867 DEGs were identified in 0d-Vs-70d, in which 5587 and 3280 genes were up-regulated and down-regulated, respectively. Totally 8709 genes were identified as 


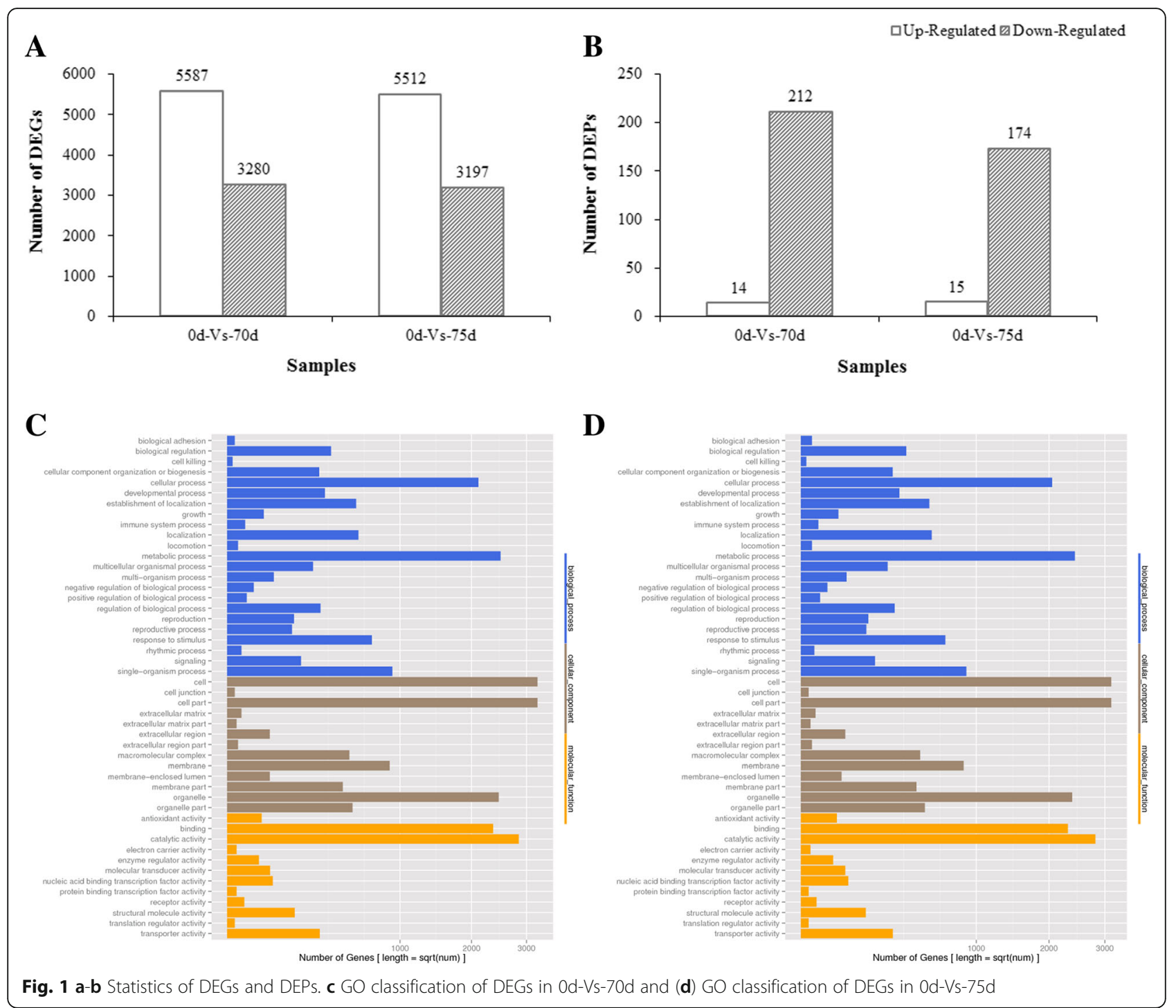

DEGs in 0d-Vs-75d, in which 5512 genes were up-regulated and 3197 genes were down-regulated. The number of DEGs identified in 0d-Vs-70d was a little bit higher than 0d-Vs-75d and more DEGs were up-regulated ( 63\%) than down-regulated in both comparisons (Fig. 1a, Additional file 5: Table S4). These genes were associated with several gene families such as plant hormone related genes (abscisic acid receptor PYR/PYL family, gibberellin receptor, AUX1 LAX family, ethylene response factor, cytokinin receptor and others), transcription factors, cytochrome $\mathrm{P} 450$, heat shock protein and so on (Additional file 5: Table S4). The expression of some genes was highly significant with $\log 2$ Ratio $\geq 10$. A list of some DEGs with $\log 2$ Ratio $\geq 10$ was shown in Additional file 6: Table S5.

A total of 4592, 3371 and 3447 proteins were identified in three biological replicates, respectively (Additional file 7: Table S6). As shown in Additional file 8: Figure S2, a total of 7413 proteins were identified by merging the data obtained from three biological replicates. Totally 2178 and 2182 proteins were detected in 0d-Vs-70d and 0d-Vs-75d, respectively. In 0d-Vs-70d, 226 proteins were identified as DEPs, in which 14 DEPs were up-regulated and 212 DEPs were down-regulated. As for 0d-Vs-75d, 189 proteins were identified as DEPs, in which 15 DEPs were up-regulated and 174 DEPs were down-regulated. However, unlike DEGs, the majority of DEPs were down-regulated in both Od-Vs-70d (94\%) and 0d-Vs-75d (92\%) (Fig. 1b, Additional file 9: Table S7).

\section{GO classification and KEGG pathway enrichment of DEGs}

DEGs were categorized into biological process, cellular component and molecular function using BLAST2GO program. According to GO classification, the main groups of each category in 0d-Vs-70d and 0d-Vs-75d were very similar as follows: main biological processes 
were metabolic and cellular; major cellular components were cell, cell part and organelle; major molecular function were catalytic activity and binding (Fig. 1c and d). In addition, DEGs were also involved in hormone stimulus, hormone mediated signaling pathway, hormone metabolic process, abscisic acid stimulus, gibberellins metabolic process and other plant hormone related processes (Additional file 5: Table S4), which revealed that plant hormone play crucial role in response to heat stress and break dormancy.

According to KEGG pathway enrichment, 5242 DEGs in 0d-Vs-70d and 5130 DEGs in 0d-Vs-75d were enriched into 126 pathways, respectively. Top 3 pathways were same (Additional file 10: Figure S3) as follows: Metabolic pathways (1267 and 1251 DEGs, respectively), Biosynthesis of secondary metabolites (726 and 725 DEGs, respectively), Plant hormone signal transduction (268 and 266 DEGs, respectively). As for plant hormone signal transduction pathway (Table 1), 268 DEGs in 0dVs-70d and 266 DEGs in 0d-Vs-75d, respectively, were involved in 8 plant hormones (Aux, CTK, GA, ABA, ET, $\mathrm{BR}$, JA and SA). The unigenes involved in plant hormone signal transduction pathway and their expression levels were given in Additional file 11: Table S8.

\section{GO classification and KEGG pathway enrichment of DEPs}

DEPs were subjected to GO classification and were categorized into biological process, cellular component and molecular function. Quite similar to DEGs, the main biological processes represented in 0d-Vs-70d were metabolic process (109) and cellular process (94), major cellular components were cell (98) and organelle (74), main molecular functions were binding (125) and catalytic activity (94) (Fig. 2a). Very similar results were also showed in 0d-Vs-75d (Fig. 2b).

As compared with all identified proteins, percentage of differential proteins in 0d-Vs-70d showed significant change in $368 \mathrm{GO}$ categories while that in OdVs-75d showed significant change in 485 GO categories. GO term with FDR $\leq 5 \%$ was considered to be significantly enriched (Additional file 12: Figure S4 and Additional file 13: Table S9).

According to KEGG pathway enrichment, 142 DEPs were enriched into 10 pathways in $0 \mathrm{~d}-\mathrm{Vs}-70 \mathrm{~d}$, the major pathways were genetic information processing (76) and carbohydrate metabolism (34) (Fig. 3a). Similarly, 124 DEPs were enriched into 10 pathways in $0 \mathrm{~d}-\mathrm{Vs}-75 \mathrm{~d}$, the major pathways were also genetic information processing (49) and carbohydrate metabolism (35) (Fig. 3b).

\section{Expression profiles of phytohormone related DEGs/DEPs}

To investigate these identified phytohormones, their expression profiles in RNA-seq and iTRAQ analysis, as well as that at mRNA levels by qPCR, were put together in Fig. 4. According to RNA-seq analysis, ABA was down-regulated while other phytohormones (GA, ET, CTK, IAA and JA) were up-regulated at germinated stages (70 d and $75 \mathrm{~d}$ ), which were also supported by qPCR results except for that of ET, CTK and IAA. Meanwhile, according to iTRAQ analysis, all of these phytohormones were down-regulated at germinated stages except that JA was up-regulated at $70 \mathrm{~d}$ and then down-regulated again at $75 \mathrm{~d}$. While these results were only supported by corresponding qPCR results of $\mathrm{ABA}$ and IAA, in which ABA was up-regulated first before 30 $\mathrm{d}$ might result from the heat shock response.

In summary, comprehensive results of RNA-seq, iTRAQ and qPCR analysis indicated that ABA might play a key role during oil palm seed germination.

\section{Expression profiles of target proteins by western blot}

Antibodies for six phytohormone related proteins were synthesized and prepared, but only one antibody (287861hz-2/C3) for ABA (ACF06553.1) was successful for validation. The other antibodies for GA (28788-1hz-10/ C13), ET (28789-1hz-2/C5), CTK (28790-1hz-12/C16), IAA (28791-1hz-9/C19), and JA (28785-1hz-10/C14) were failed to synthesize. The western blot results showed that the antibody for ABA has a specific band at about $17 \mathrm{kDa}$ in samples $0 \mathrm{~d}, 15 \mathrm{~d}, 30 \mathrm{~d}, 45 \mathrm{~d}$ and $60 \mathrm{~d}$ (Fig. 5a). Normalization results (Table 2) showed that ABA highly expressed in early stages until $30 \mathrm{~d}$ and then decreased dramatically to $14 \%$ of the control at the end of heat treatment $(60 \mathrm{~d})$, further decreased to $1 \%$ of the control at the beginning of seed germination $(70 \mathrm{~d})$ and completely disappeared at $75 \mathrm{~d}$ (Fig. 5b).

\section{Changes in endogenous phytohormones during seed germination}

The concentration of endogenous phytohormones (ABA, GA, ET, CTK, IAA, and JA) in the embryos during seed germination was determined using LCMS/MS system. Results showed that endogenous ABA decreased rapidly to about $9 \%$ of the control at $30 \mathrm{~d}$ and then stayed at very low levels until germination. GA responded rapidly since the very beginning of heat treatment, it increased till the end of heat treatment $(60 \mathrm{~d})$ and then decreased to approximately that of the control level at $75 \mathrm{~d}$. While CTK hardly changed at the beginning of heat treatment, it increased dramatically at $45 \mathrm{~d}$ and $60 \mathrm{~d}$, and then similar decreases to GA were also observed since germination (70 d), suggesting that endogenous GA and CTK experienced similar changes as a result of heat treatment. While JA was not evident throughout the process except for a sudden rise at $15 \mathrm{~d}$. As for IAA, it barely changed during heat treatment and then increased rapidly along with germination since $70 \mathrm{~d}$ 
Table 1 DEGs involved in plant hormone signal transduction pathway

\begin{tabular}{|c|c|c|c|c|c|c|}
\hline \multirow[t]{2}{*}{ Components } & \multicolumn{3}{|c|}{ od-Vs-70d } & \multicolumn{3}{|c|}{ Od-Vs-75d } \\
\hline & DEGs & $\uparrow r e g u l a t e d$ & $\downarrow$ regulated & DEGs & $\uparrow$ regulated & $\downarrow$ regulated \\
\hline Auxin & 45 & 36 & 9 & 41 & 32 & 9 \\
\hline$A \cup \times 1$ & 5 & 5 & 0 & 4 & 4 & 0 \\
\hline $\mathrm{TIR} 1$ & 5 & 3 & 2 & 3 & 2 & 1 \\
\hline AUX/IAA & 14 & 12 & 2 & 14 & 11 & 3 \\
\hline ARF & 9 & 6 & 3 & 9 & 6 & 3 \\
\hline $\mathrm{GH} 3$ & 3 & 3 & 0 & 3 & 3 & 0 \\
\hline SAUR & 9 & 7 & 2 & 8 & 6 & 2 \\
\hline Cytokinin & 40 & 30 & 10 & 41 & 30 & 11 \\
\hline CRE1 & 19 & 12 & 7 & 18 & 11 & 7 \\
\hline B-ARR & 18 & 15 & 3 & 20 & 17 & 3 \\
\hline A-ARR & 3 & 3 & 0 & 3 & 2 & 1 \\
\hline Gibberellin & 27 & 23 & 4 & 27 & 23 & 4 \\
\hline GID1 & 11 & 10 & 1 & 12 & 11 & 1 \\
\hline GID2 & 2 & 2 & 0 & 2 & 2 & 0 \\
\hline DELLA & 14 & 11 & 3 & 13 & 10 & 3 \\
\hline Abscisic acid & 43 & 31 & 12 & 45 & 33 & 12 \\
\hline PYR/PYL & 8 & 8 & 0 & 8 & 8 & 0 \\
\hline $\mathrm{PP} 2 \mathrm{C}$ & 30 & 21 & 9 & 31 & 22 & 9 \\
\hline SnRK2 & 1 & 0 & 1 & 2 & 1 & 1 \\
\hline$A B F$ & 4 & 2 & 2 & 4 & 2 & 2 \\
\hline Ethylene & 28 & 15 & 13 & 30 & 15 & 15 \\
\hline ETR & 2 & 0 & 2 & 2 & 0 & 2 \\
\hline CTR1 & 13 & 7 & 6 & 12 & 5 & 7 \\
\hline MPK6 & 3 & 3 & 0 & 3 & 3 & 0 \\
\hline EIN2 & 4 & 0 & 4 & 4 & 0 & 4 \\
\hline EBF $1 / 2$ & 0 & 0 & 0 & 1 & 0 & 1 \\
\hline ERF $1 / 2$ & 6 & 5 & 1 & 8 & 7 & 1 \\
\hline Brassinosteroid & 42 & 33 & 9 & 37 & 30 & 7 \\
\hline BAK1 & 13 & 10 & 3 & 10 & 7 & 3 \\
\hline BRI1 & 9 & 7 & 2 & 8 & 7 & 1 \\
\hline BSK & 1 & 1 & 0 & 1 & 1 & 0 \\
\hline BSU1 & 1 & 0 & 1 & 0 & 0 & 0 \\
\hline BZR1/2 & 6 & 4 & 2 & 6 & 4 & 2 \\
\hline $\mathrm{TCH} 4$ & 7 & 6 & 1 & 8 & 7 & 1 \\
\hline CYCD3 & 5 & 5 & 0 & 4 & 4 & 0 \\
\hline Jasmonic acid & 30 & 26 & 4 & 32 & 29 & 3 \\
\hline JAR1 & 2 & 2 & 0 & 2 & 2 & 0 \\
\hline COI1 & 1 & 0 & 1 & 1 & 0 & 1 \\
\hline$J A Z$ & 11 & 11 & 0 & 11 & 11 & 0 \\
\hline MYC2 & 16 & 13 & 3 & 18 & 16 & 2 \\
\hline Salicylic acid & 13 & 9 & 4 & 13 & 10 & 3 \\
\hline NPR1 & 2 & 2 & 0 & 1 & 1 & 0 \\
\hline TGA & 10 & 6 & 4 & 11 & 8 & 3 \\
\hline
\end{tabular}


Table 1 DEGs involved in plant hormone signal transduction pathway (Continued)

\begin{tabular}{|c|c|c|c|c|c|c|}
\hline \multirow[t]{2}{*}{ Components } & \multicolumn{3}{|c|}{ 0d-Vs-70d } & \multicolumn{3}{|c|}{ Od-Vs-75d } \\
\hline & DEGs & $\uparrow$ regulated & $\downarrow$ \regulated & DEGs & 个regulated & $\overline{\downarrow \text { regulated }}$ \\
\hline PR1 & 1 & 1 & 0 & 1 & 1 & 0 \\
\hline Total & 268 & 203 & 65 & 266 & 202 & 64 \\
\hline
\end{tabular}

(Fig. 6), indicating that the heat treatment has no effect on endogenous IAA. These results suggested that heat treatment can eliminate endogenous $\mathrm{ABA}$ and oil palm seeds are able to germinate only after endogenous ABA decreased to a very low level by heat treatment. At least 30 days of heat treatment is necessary to break dormancy.

Effect of exogenous phytohormones on seed germination Seed germination results showed that germination rates of all exogenous treatments were lower than the control (38\%). Remarkably, with the increasing concentration of ABA treatments, the germination rate decreased rapidly from $24 \%(10 \mathrm{mg} / \mathrm{L})$ to $16 \%(100 \mathrm{mg} / \mathrm{L})$ and $6 \%$ $(1000 \mathrm{mg} / \mathrm{L})$, which was only 63,42 and $16 \%$ of the control, respectively, indicating that exogenous ABA could inhibit seed germination again even after endogenous ABA already decreased to a very low level by heat treatment. However, germination rates of exogenous GA and IAA treatments barely changed among different concentrations (Fig. 7a).

\section{Discussion}

Oil palm seeds are difficult to germinate under natural conditions. Heat treatment is an effective method to break dormancy for rapid germination [10] and phytohormones are also known as one of the key players that control seed dormancy and germination [11, 23]. However, related mechanism stays unclear in oil palm.
In this study, RNA-seq and iTRAQ analysis were applied to investigate DEGs and DEPs related to seed germination. RNA-seq analysis identified 8867 and 8709 DEGs in 0d-Vs-70d and 0d-Vs-75d, while iTRAQ analysis identified 226 and 189 DEPs in 0d-Vs-70d and 0d-Vs-75d, respectively. More DEGs were up-regulated $(\sim 63 \%)$ in RNA-seq while the majority of DEPs were down-regulated $(\sim 93 \%)$ in iTRAQ. In general, the major categories resulted from GO classification of both DEGs and DEPs were very similar as follows: metabolic and cellular in biological processes, cell and organelle in cellular components, catalytic activity and binding in molecular function. However, the expression profiles of some identified phytohormones at mRNA levels were not completely in agreement with that at protein levels (Fig. 4). This may be due to post-transcriptional and post-translational regulating mechanisms [21, 22, 24].

According to RNA-seq analysis, over 260 DEGs related to 8 phytohormones were involved in plant hormone signal transduction pathway (ko04075), and 6 of them (ABA, GA, ET, CTK, IAA and JA) were also identified by iTRAQ, indicating that phytohormones are deeply involved in oil palm seed germination process.

Endogenous ABA is the key factor result in oil palm seed dormancy. Both RNA-seq and iTRAQ results showed that ABA decreased after heat treatment, and corresponding validations by $\mathrm{qPCR}$ and western blot also revealed the decrease of endogenous ABA. Although ABA increased first at early stages during heat treatment in the present study, it might result from the heat shock

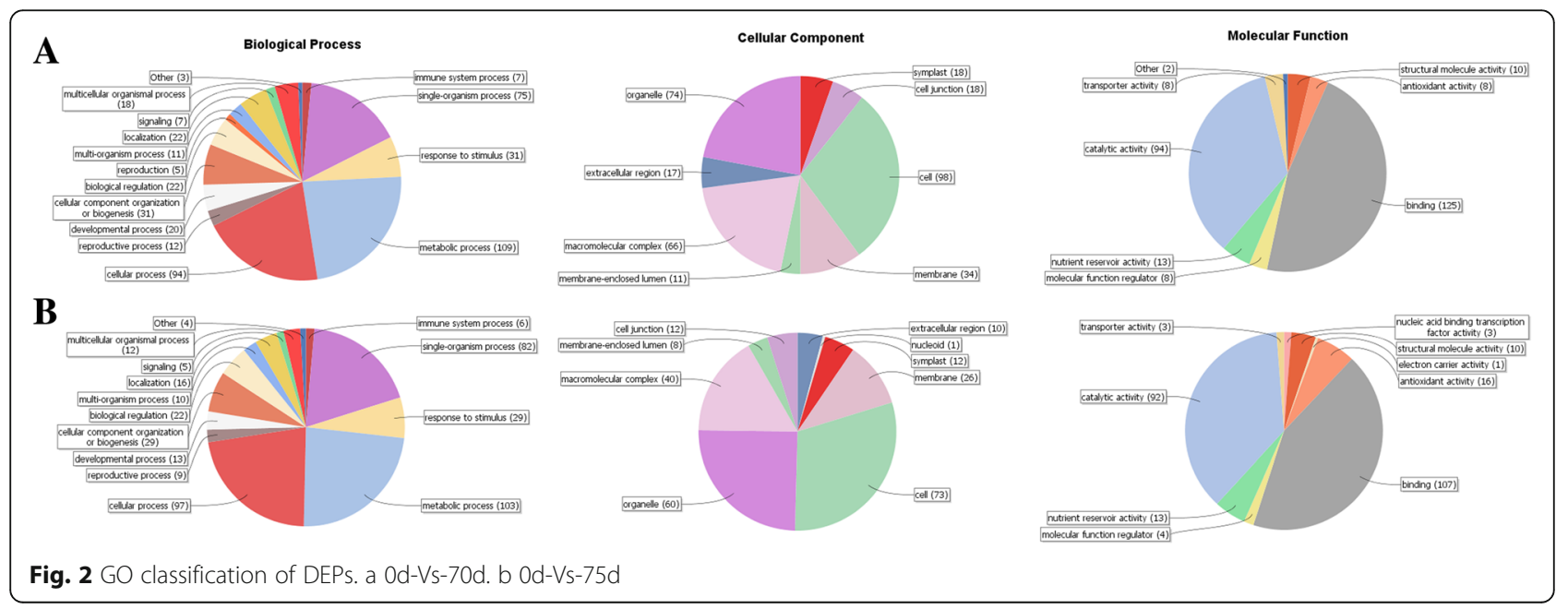



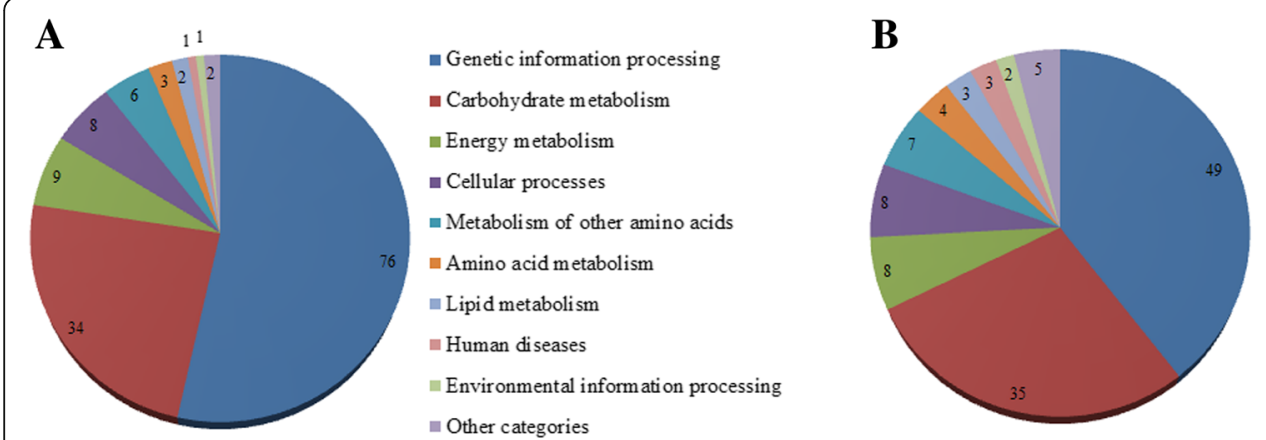

- Genetic information processing

a Carbohydrate metabolism

Amino acid metabolism

- Cellular processes

- Metabolism of other amino acids

Environmental information processing

Energy metabolism

घnzyme families

Metabolism of cofactors and vitamins

Other categories

Fig. 3 KEGG pathway enrichment of DEPs. a Od-Vs-70d. b 0d-Vs-75d

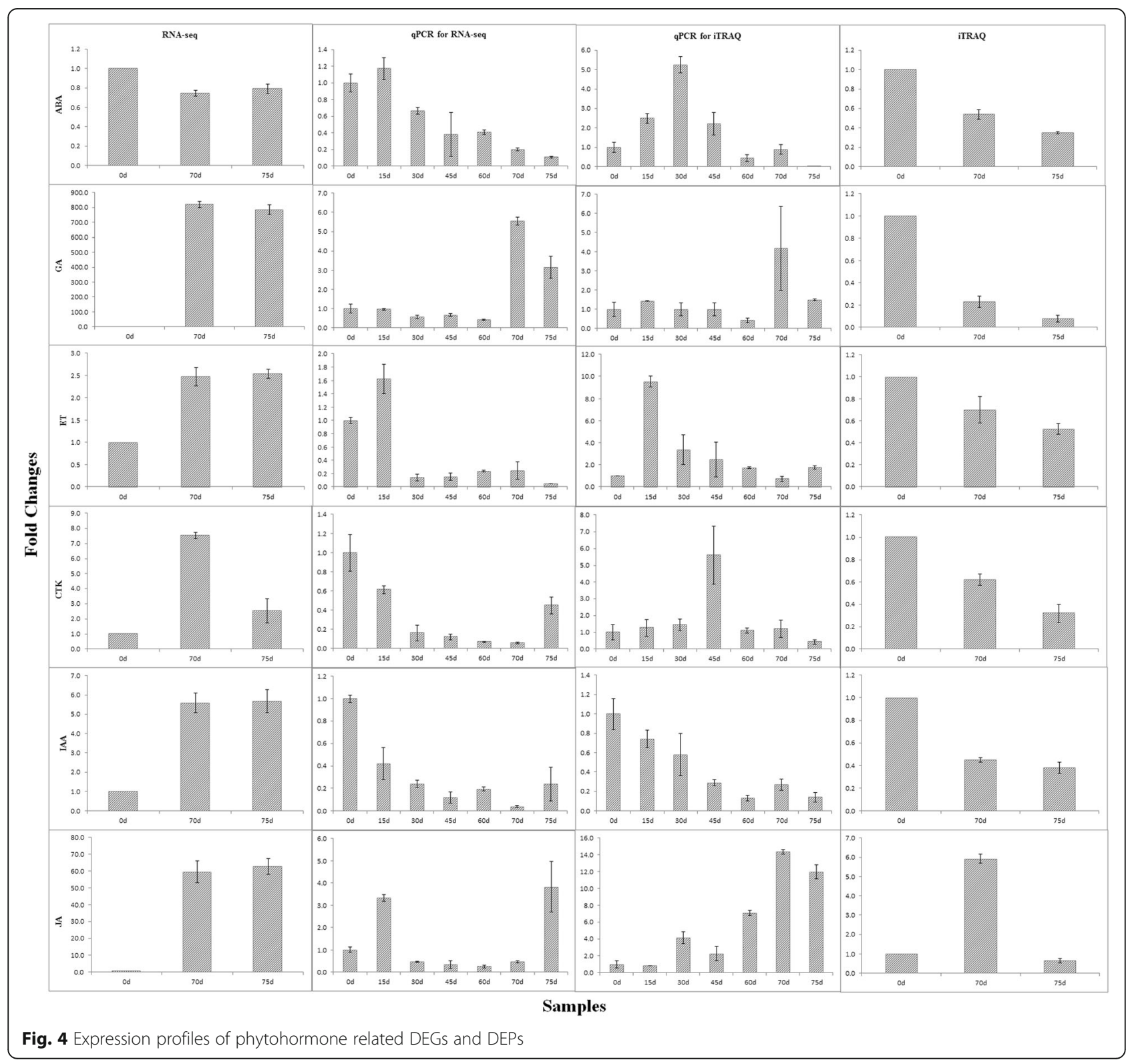




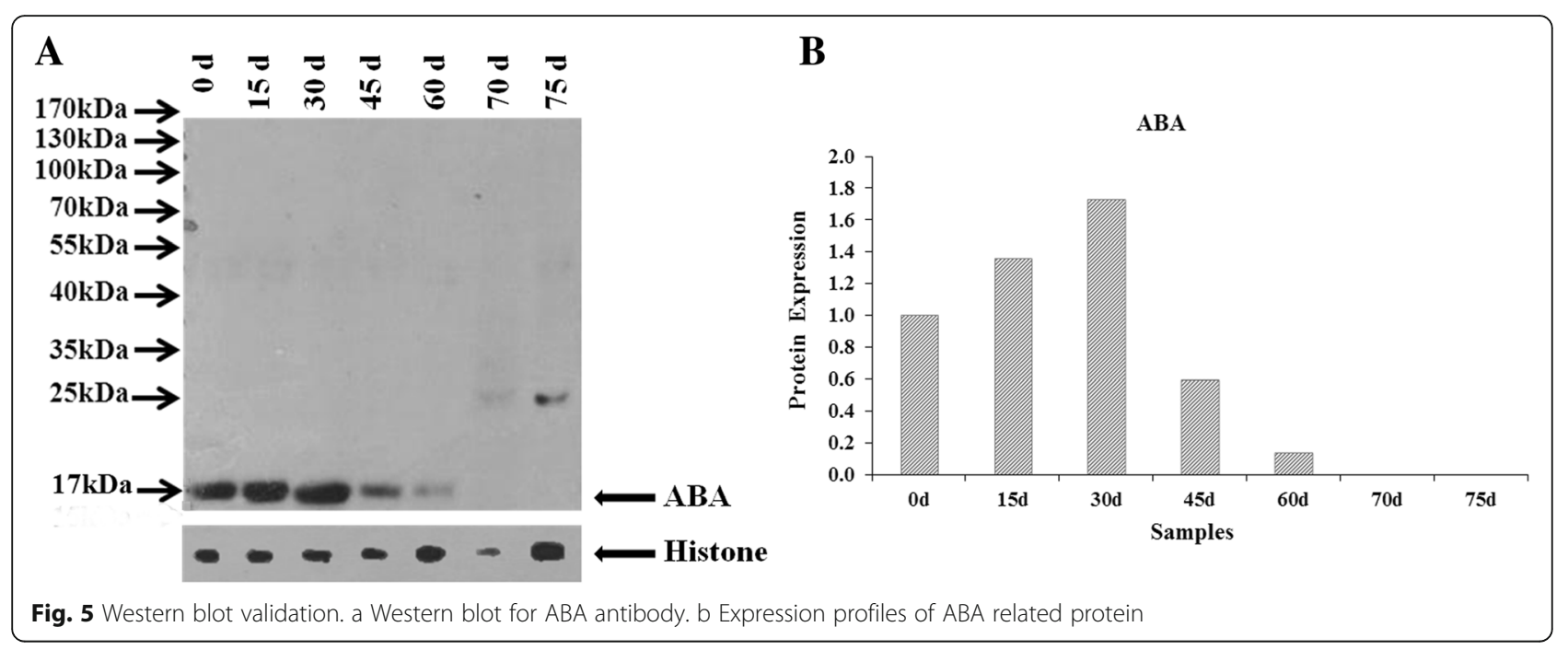

response, which could be always related to rapid increase of endogenous $\mathrm{ABA}$ in crop plants under abiotic stress $[25,26]$. Besides, the most direct evidence resulted from the determination of endogenous phytohormones, in which ABA decreased rapidly to only about $9 \%$ of the control at $30 \mathrm{~d}$ and remained at very low levels thereafter till germination. These results suggested that heat treatment could eliminate endogenous $\mathrm{ABA}$ to break seed dormancy and at least 30 days of heat treatment might be necessary, which was in agreement with previous results in oil palm [18]. Studies in other crops also gave similar results. ABA could positively regulate seed dormancy while GA could break seed dormancy and induce germination [27, 28]; ABA accumulated during seed maturation to initiate dormancy, however, it was down-regulated while GA was up-regulated before the onset of germination process [14]. Furthermore, the seed germination after heat treatment was highly suppressed again by exogenous ABA treatments at the imbibition stage (Fig. 7a), which confirmed the crucial role of ABA. The oil palm seeds could be able to germinate only after endogenous ABA was almost completely eliminated by heat treatment.

Endogenous GA and CTK may antagonize ABA suppression to seed germination. ABA decreased rapidly

Table 2 Western blot analysis

\begin{tabular}{llllllll}
\hline Samples & $0 \mathrm{~d}$ & $15 \mathrm{~d}$ & $30 \mathrm{~d}$ & $45 \mathrm{~d}$ & $60 \mathrm{~d}$ & $70 \mathrm{~d}$ & $75 \mathrm{~d}$ \\
\hline ABA & 17.79 & 25.28 & 31.15 & 10.62 & 3.89 & 0.06 & 0.07 \\
Histone & 9.06 & 9.49 & 9.22 & 9.14 & 14.39 & 4.51 & 25.18 \\
ABA/Histone & 1.96 & 2.66 & 3.38 & 1.16 & 0.27 & 0.01 & 0.00 \\
Normalization & 1.00 & 1.36 & 1.72 & 0.59 & 0.14 & 0.01 & 0.00 \\
\hline
\end{tabular}

Note: Values represent protein expression levels. Expression of each sample was divided by $A B A / H i s t o n e ~(1.96)$ for normalization since the very beginning of heat treatment and almost disappeared since $30 \mathrm{~d}$; while on the contrary, both GA and CTK increased by heat treatment, suggesting that endogenous GA and CTK may antagonize ABA to break seed dormancy. Previous study also showed that cytokinin antagonizes ABA suppression to seed germination of Arabidopsis by down-regulating ABI5 expression [29]. However, Arabidopsis mutants without CTK receptors had more rapid seed germination [30], indicating that CTK may inhibit germination and further detailed investigations are still needed. On the other hand, endogenous GA and CTK decreased since germination $(70 \mathrm{~d})$, suggesting that they might be further involved in embryo development after successful germination. As for JA, it was not evident throughout the germination except for a sudden rise at $15 \mathrm{~d}$, suggesting that JA may be not important in oil palm seed germination process. In summary, endogenous ABA is responsible for seed dormancy, while GA and CTK may be related to dormancy release.

Recent study [31] revealed that ABA levels in the rice seeds stressed at $35^{\circ} \mathrm{C}$ decreased with increasing time of heat stress, while GA3 levels increased as compared with non-stressed seeds. Their results are in agreement with our results, suggesting that hormonal response to heat stress observed in oil palm is similar with rice.

Endogenous IAA in oil palm seeds was not obviously affected by heat treatment. Although IAA increased rapidly along with germination since $70 \mathrm{~d}$ (Fig. 6), it might result from the vigorous growth of germinated embryos, because Auxin involved in almost all aspects of plant development including shoot and root developments [14]. However, exogenous IAA could inhibit seed germination. Previous study showed that exogenous IAA could delay seed germination as the complement of $\mathrm{ABA}$ in 


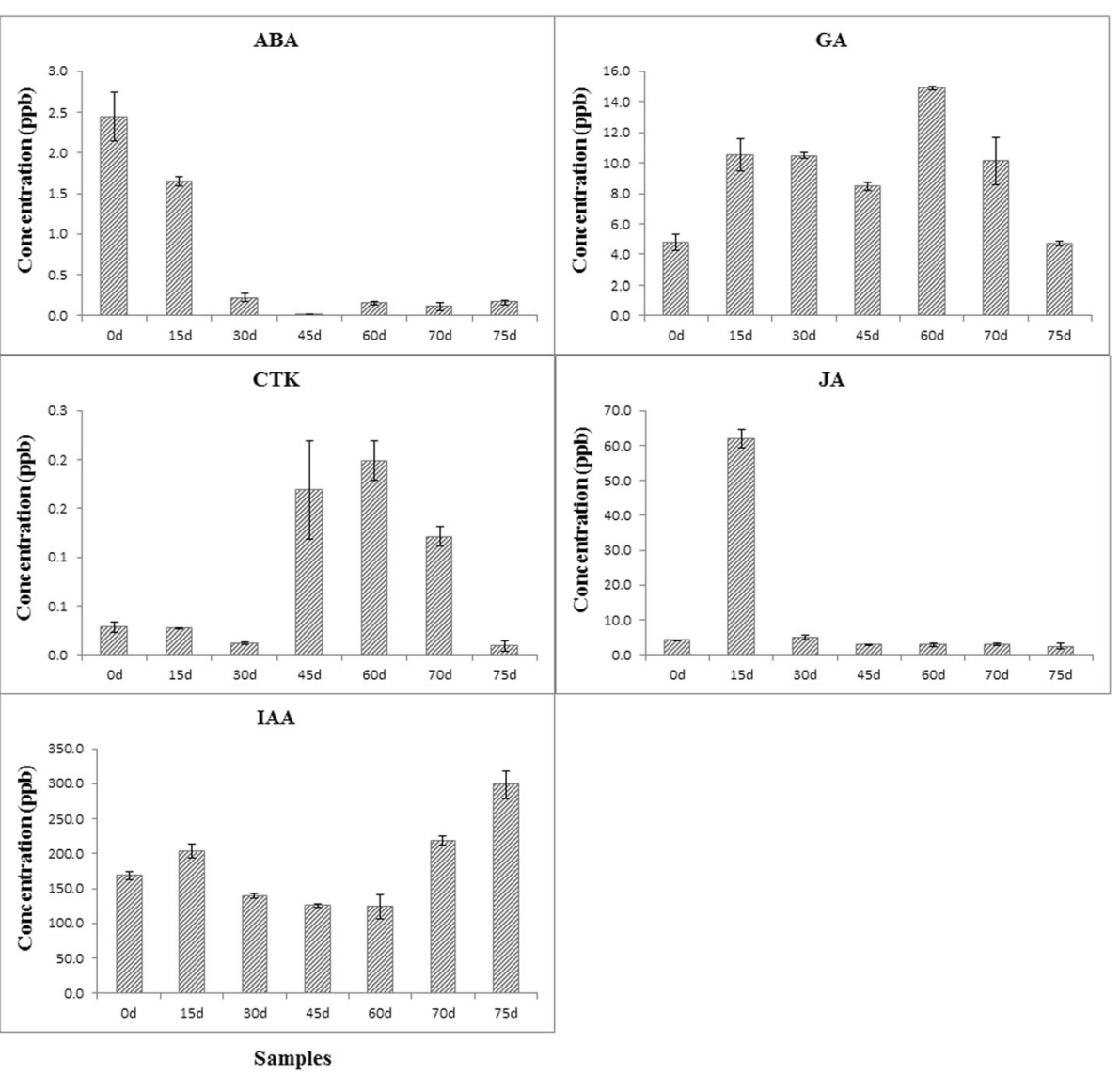

Fig. 6 Changes in endogenous phytohormones during seed germination

preharvest sprouting of wheat [32]. Similarly, earlier studies in Arabidopsis reported that exogenous auxin could enhance the inhibition on seed germination by ABA, but cannot inhibit seed germination in the absence of ABA [5, 33, 34]. Therefore, endogenous IAA in oil palm seeds might not be affected by heat treatment while exogenous IAA could inhibit seed germination.

\section{Conclusions}

In conclusion, integrative omics analysis using RNA-seq and iTRAQ along with validations by $\mathrm{qPCR}$, western blot, endogenous quantification of phytohormones and exogenous phytohormones treatments, revealed that phytohormones are deeply involved in oil palm seed germination and ABA act as an inhibitor, similarly as described in most plant species. Heat treatment improves oil palm seed germination by eliminating endogenous ABA and breaking dormancy, while GA and CTK may also involve in dormancy release. At least 30 days of heat treatment is necessary to break dormancy. These results could be useful for oil palm seedling propagation and may be also applicable in other palm species.

\section{Methods}

\section{Embryo preparation}

Oil palm seeds were collected from the oil palm germplasm nursery in Coconut Research Institute, Chinese Academy of Tropical Agricultural Sciences, Wenchang, China. Dry heat method was used for seed germination according to Corley [8] as follows: The seeds were dried naturally under the shade to reach the moisture content of $18 \%$ and kept in tightly sealed polythene bags, and then were placed in the germinator at $39^{\circ} \mathrm{C}$ to break dormancy (heat treatment). During heat treatment, seeds were collected at $15 \mathrm{~d}, 30 \mathrm{~d}$, $45 \mathrm{~d}$, and $60 \mathrm{~d}$, respectively. Thereafter, the seeds were soaked in distilled water for about 2 days to reach the moisture content of $22 \%$ and then placed at $27^{\circ} \mathrm{C}$ for germination. The seeds were then sectioned and embryos were collected from both non-germinated $(15 \mathrm{~d}, 30 \mathrm{~d}, 45 \mathrm{~d}, 60 \mathrm{~d})$ and germinated seeds (70 d, $75 \mathrm{~d}$ ). Embryos of untreated seeds $(0 \mathrm{~d})$ were collected before treatment as the control and kept in freezer at $-80^{\circ} \mathrm{C}$. About $2 \mathrm{~g}$ of embryos from each sample ( $0 \mathrm{~d}, 15 \mathrm{~d}, 30 \mathrm{~d}, 45 \mathrm{~d}, 60 \mathrm{~d}, 70 \mathrm{~d}$ and $75 \mathrm{~d})$ were collected (Fig. 7b) and frozen in liquid nitrogen immediately. Thereafter, they were kept in freezer at $-80^{\circ} \mathrm{C}$ for the following analyses. 

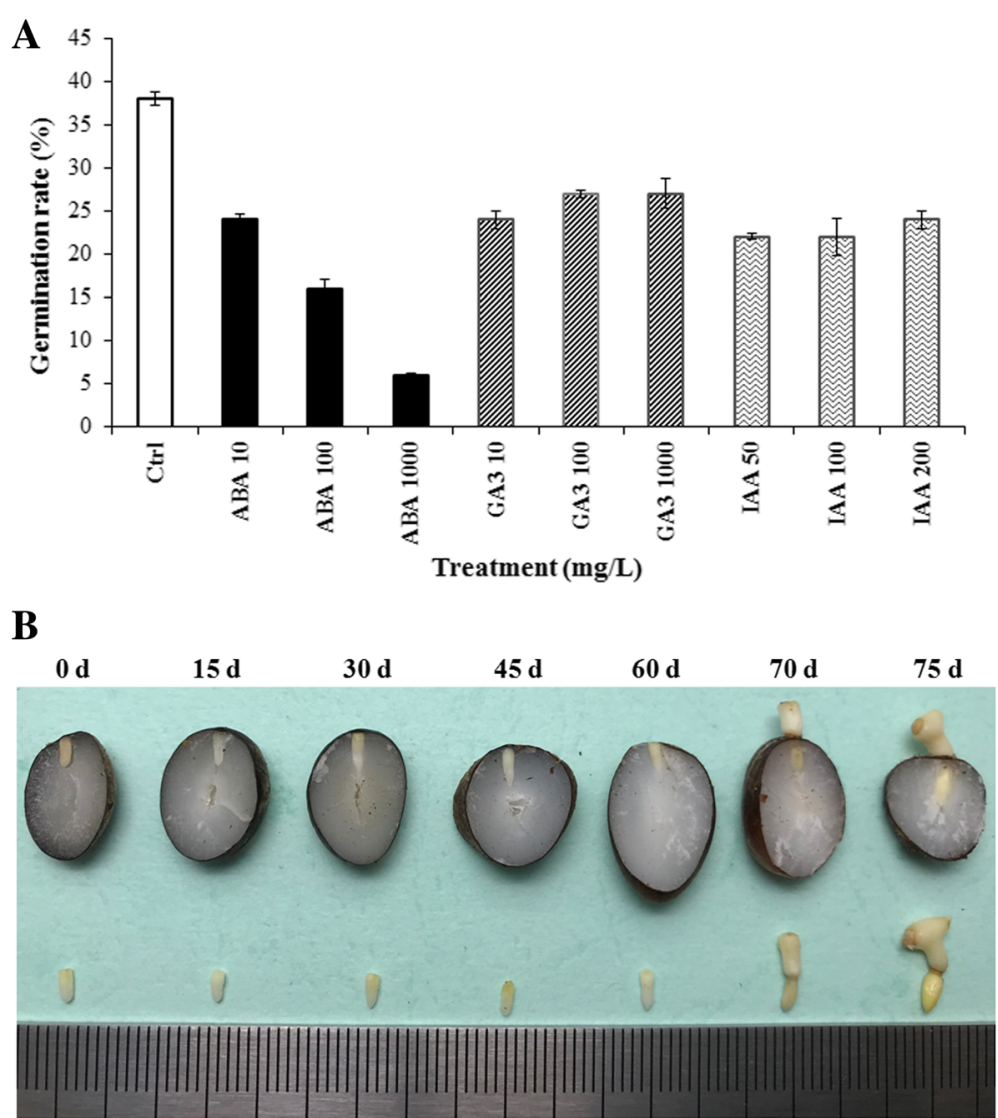

Fig. 7 a Effect of exogenous phytohormones on seed germination. The treatment with distilled water was taken as control (Ctrl) and 100 oil palm seeds were used in each treatment. $\mathbf{b}$ Germination of oil palm seeds

For RNA-seq and iTRAQ analysis, embryos of control $(0 \mathrm{~d})$ and germinated $(70 \mathrm{~d}$ and $75 \mathrm{~d})$ were selected, while the rest embryos ( $15 \mathrm{~d}, 30 \mathrm{~d}, 45 \mathrm{~d}, 60 \mathrm{~d})$ without obvious morphological changes during the heat treatment process were not used. The experiment included three biological replicates for each stage.

\section{RNA extraction and RNA-seq analysis}

Total RNA of each sample was extracted using Trizol Reagent (invitrogen, USA) according to the manufacturer's instruction and treated with DNaseI (Takara, Japan) to degrade any possible DNA contamination. Concentration and purity of each RNA sample was determined using ND-2000 spectrophotometer (NanoDrop, USA), and RNA integrity was examined by $1.5 \%$ agarose gel electrophoresis. Identical RNAs of each sample were used for RNAseq analysis and the following $\mathrm{qPCR}$ validation.

Total RNA of embryos ( $0 \mathrm{~d}, 70 \mathrm{~d}$ and $75 \mathrm{~d}$ ) were submitted to BGI (Shenzhen, China) for RNA-seq analysis. The library was constructed and then sequenced using Illumina Hiseq 2000 by BGI
(Shenzhen, China). After sequencing, raw reads containing low quality reads, reads with adapters, and reads with unknown bases more than $10 \%$ were filtered before data analysis. Clean Reads were used for downstream bioinformatics analysis. The clean reads were mapped to reference genome using BWA [35]. Gene expression level was quantified using RNA-seq by expectation maximization (RSEM) [36]. The gene expression levels were calculated by fragments per kilobase of transcripts per million fragments mapped (FPKM). Differentially expressed genes between two groups were detected with Noiseq method [37]. In this analysis, differentially expressed genes were screened with the foldchange $\geq 2$ and probability $\geq 0.8$. Then, Gene Ontology (GO) classification and Kyoto Encyclopedia of Genes and Genomes (KGGG) pathway enrichment of differentially expressed genes (DEGs) were analyzed to annotate the DEGs.

\section{Protein extraction and ITRAQ analysis}

Proteins were extracted with NitroExtra ${ }^{\mathrm{Tm}}$ (Cat. PEX001-250ML, N-Cell Technology, China). Sample debris were removed by high centrifugation at 100,000×g, using 
$\mathrm{SW}-28$ rotor for $2 \mathrm{~h}$ at $10^{\circ} \mathrm{C}$. After centrifugation, proteins were precipitated with 1:3 (Sample to Acetone) cold acetone at $-20^{\circ} \mathrm{C}$ overnight. Precipitated proteins were washed twice with cold acetone and finally re-suspended in $8 \mathrm{M}$ urea after protein precipitate had been air dried.

Proteins of embryos ( $0 \mathrm{~d}, 70 \mathrm{~d}$ and $75 \mathrm{~d})$ were submitted to N-Cell Technology (Shenzhen, China) for iTRAQ analysis. Proteins were alkylated and then determined by DC Assay Kit (Cat. 500-0111, BioRad). Trypsin digestion was performed in $100 \mathrm{mM}$ TEAB (pH 8, T7408, Sigma) and the trypsin digest was incubated at $37^{\circ} \mathrm{C}$ for $18 \mathrm{~h}$. Digested proteins were desalted by $\mathrm{C} 18$ column and dried in spin vacuum. Then $100 \mu \mathrm{g}$ of desalted peptides from each sample was chemically labeled with iTRAQ 8-plex reagent (Cat. 4, $466,096)$ in $100 \mathrm{mM}$ TEAB according to manufacturer's protocol. After desalting, differentially labeled peptide samples were re-suspended in SCX for peptide fractionation. Totally 53 of $1 \mathrm{~mL}$ fractions were collected and further combined into 10 fractions based on the number of proteins identified in each $5 \mathrm{~min}$ fraction. Each fraction was desalted with ZipTip (Cat. ZTC18S960, Millipore) and dried in spin vacuum for LC-MS/MS analysis by AB SCIEX 6600 (USA).

Raw data files were transformed into Mascot Generic Format (MGF) and mzXML format using OpenMS. The MGF files were searched against the NCBI and common MS contaminant database using Mascot (Matrix Science) software. The tolerance for MS1 and MS2 error was $20 \mathrm{ppm}$ and $50 \mathrm{mmu}$ respectively. Caramidomethylation $(+57 \mathrm{Da})$ was added as fixed modification while iTRAQ 8-Plex $(\mathrm{K} / \mathrm{N})$ and Oxidation $(\mathrm{M})$ were added as variable modifications. A maximum of 2 trypsin miss cleavages were allowed. The instrument type was chosen as ESI-QTOF. The mass input was assumed to be monoisotopic mass. Decoy database was used for the estimation of false discovery rate (FDR). The protein ratios of $P<0.05$ with $5 \%$ FDR correction were filtered as differential proteins for following analyses.

\section{qPCR validation}

Complementary DNA (cDNA) from total RNA was prepared using RevertAid ${ }^{\mathrm{m}}$ first strand cDNA synthesis kit (Fermentas, Lithuania) according to the manufacturer's protocol. Phytohormone related DEGs/DEPs were selected from RNA-seq/iTRAQ for expression validation after protein sequences were translated to nucleotide sequences using NCBI. Primers (Tables 3 and 4) were designed with Primer-BLAST and synthesized by BGI (Shenzhen, China). PCR optimization was performed in PCR Thermal Cycler Dice ${ }^{\text {rm }}$ TP600 (TaKaRa, Japan).

The qPCR was performed on ABI-7900HT (Applied Biosystems, USA) using PowerUp SYBR Green Master Mix (Applied Biosystems, USA) under the following conditions: $95^{\circ} \mathrm{C}$ for $10 \mathrm{~min}$, followed by 40 cycles at $95^{\circ} \mathrm{C}$ for $15 \mathrm{~s}$ and $60^{\circ} \mathrm{C}$ for $1 \mathrm{~min}$ in 384 well optical plates. Each reaction mixture was $10 \mu \mathrm{L}$ containing $1 \mu \mathrm{L}$ of $50 \mathrm{ng} / \mu \mathrm{L}$ cDNA, $5 \mu \mathrm{L}$ of 2X PowerUp SYBR Green Master Mix, $0.5 \mu \mathrm{L}$ of each $10 \mu \mathrm{M}$ forward and reverse primers. The raw data were analyzed using ABI-7900HT software and housekeeping gene Actin was used as an endogenous control for normalization of gene expression. Comparative Ct method was used for qPCR normalization and each sample was detected in four replicates.

\section{Antibody preparation and western blot validation}

According to protein sequence of each phytohormone related DEP (ABA, GA, ET, CTK, IAA and JA), ten peptides were designed and synthesized, respectively, and then were injected to rabbits for antibody preparation by Abmart Biomedicine (Shanghai, China). Only successful antibodies were used for western blot validation.

SDS-PAGE and immunoblotting were performed according to standard procedures. Cell membranes were incubated with antisera that were used against one of the following individual proteins: $\mathrm{C}-24$ sterol reductase (ERG4), HMG-CoA synthase (ERG13), C-4 sterol methyl oxidase (ERG25), and Actin (each 1:1000 dilution). ERG4 and ERG25 were customized from Abmart

Table 3 Target genes from RNA-seq and corresponding primers for qPCR

\begin{tabular}{llll}
\hline Name & Gene ID & Primer sequences (5'-3') & Amplicon length (bp) \\
\hline ABA & XM_010922729.2 & F- TGGTGGATCGTACGTGGTC & 82 \\
GA & XM_010921546.2 & R- CACTTGACGATTGTGTCCGC & 198 \\
ET & JN203269.1 & F-AGCCAACCCACTAGACCAAA & 118 \\
CTK & NM_001156290.2 & F- TTGACTCAGGCACAACTTGC & 86 \\
IAA & R-GCCAGCTACGATTAGTTCCCT & 186 \\
JA & FC146057.1 & F- GACGTGCCACTTCACAATGG & 186 \\
& NM_001055402.1 & F-AGGGGCTACGTGCTAGAGAA & 103 \\
\hline
\end{tabular}


Table 4 Target proteins from iTRAQ and corresponding primers for qPCR

\begin{tabular}{|c|c|c|c|}
\hline Name & Protein ID & Primer sequences $\left(5^{\prime}-3^{\prime}\right)$ & Amplicon length (bp) \\
\hline$\overline{\mathrm{ABA}}$ & XP_010918764.1 & $\begin{array}{l}\text { F- GTTGGAGGAAGCCGATCCA } \\
\text { R- TGAACACCAGGTGCAACAGA }\end{array}$ & 127 \\
\hline GA & XP_010904836.1 & $\begin{array}{l}\text { F- CTCCTTICGGCGAGATTGGT } \\
\text { R- CTCTATCTCAAGCCGGGCAC }\end{array}$ & 71 \\
\hline ET & XP_010915532.1 & $\begin{array}{l}\text { F- TCCCCCATCCAAAATCCAAACA } \\
\text { R- ATTTGTACTTCGTGCCCCCTT }\end{array}$ & 113 \\
\hline CTK & XP_010906323.1 & $\begin{array}{l}\text { F- TCGGCAAAAGATGCTTGGGA } \\
\text { R- CCAGACCCTTCTTACGCTACA }\end{array}$ & 79 \\
\hline IAA & XP_010917603.1 & $\begin{array}{l}\text { F- AGGAGAATGGAAGGTGGAGGA } \\
\text { R- CAAGCCTTAGCTCGGTTGCT }\end{array}$ & 70 \\
\hline$J A$ & XP_010908911.1 & $\begin{array}{l}\text { F- AACAGGGCCTCACTCTGGTA } \\
\text { R- GAACCGGGCTAATGATGCCT }\end{array}$ & 193 \\
\hline
\end{tabular}

Biomedicine (Shanghai, China). ERG13 antibody was purchased from LifeSpan Biosciences (Seattle, USA) and Actin antibody was purchased from Agrisera (Vännäs, Sweden). The secondary antibody was goat anti rabbit IgG $(1: 10,000)$ conjugated with alkaline phosphatase. The bands were visualized by a premixed BCIP/NBT substrate solution (Sigma-Aldrich, USA). Histone antibody was used as control.

\section{Determination of endogenous phytohormones}

Endogenous phytohormones were analyzed using the XEVO TQ-S system (WATERS, USA) with a chromatographic column (ACQUITY UPLC BEH C18). The fine powder $(0.2 \mathrm{~g})$ of each sample was soaked in $1.5 \mathrm{~mL}$ of extraction buffer (Methanol: Ultrapure water: Methanolic acid =15: 4: 1). After vortexing at $60 \mathrm{HZ}$ for $1 \mathrm{~min}$, samples were centrifuged at $10000 \mathrm{rpm}$ for $15 \mathrm{~min}$ at $4{ }^{\circ} \mathrm{C}$. Then, $1 \mathrm{~mL}$ of supernatant was collected and filtered through a $0.22 \mu \mathrm{m}$ filter membrane. Finally, each sample was transferred into a $2 \mathrm{~mL}$ LC/MS glass vial for LC-MS/MS analysis. The mobile phases and gradient were as follows: mobile phase A, Methanol; mobile phase $\mathrm{B}$, Ultrapure water. The flow rate was set to 0.4 $\mathrm{mL} / \mathrm{min}$. The gradient program was as follows: $25 \% \mathrm{~A}$ and $75 \% \mathrm{~B}$ for $0 \mathrm{~min}$; $25 \% \mathrm{~A}$ and $75 \% \mathrm{~B}$ for $0.5 \mathrm{~min} ; 2 \%$ $\mathrm{A}$ and $98 \% \mathrm{~B}$ for $0.51 \mathrm{~min} ; 2 \% \mathrm{~A}$ and $98 \% \mathrm{~B}$ for $1 \mathrm{~min}$; $100 \%$ A for $1.5 \mathrm{~min}$; 100\% A for $2 \mathrm{~min} ; 25$ and $75 \% \mathrm{~B}$ for $3 \mathrm{~min} ; 25 \% \mathrm{~A}$ and $75 \% \mathrm{~B}$ for $4 \mathrm{~min}$. Multiple reaction monitoring (MRM) detection method was used for the quantification of all analytes. The mass spectrum parameters are as follows: capillary voltage, $2.0 \mathrm{kV}$; capillary temperature, $380{ }^{\circ} \mathrm{C}$; sheath gas flow rate, $60 \mathrm{~L} / \mathrm{N}$; Aux gas flow rate, $600 \mathrm{~L} / \mathrm{N}$; MSMS collision gas, argon; collision gas flow rate, $0.18 \mathrm{~mL} / \mathrm{min}$. Each sample was extracted three times. The chemical standards of ABA (CAS 21293298), GA (CAS 77065), CTK (CAS 525791), IAA (CAS 87514) and JA (CAS 39924522) were purchased from Sigma-Aldrich (USA) and used to create calibration curves.

\section{Validation with exogenous phytohormones}

Three phytohormones (ABA, GA, IAA) identified from this work were applied individually to validate the effect of exogenous phytohormones on seed germination. The same dry heat method was used for seed germination according to Corley [8]. After heat treatment for 60 days to break dormancy, seeds were soaked in distilled water for 2 days along with phytohormone treatments as follows: ABA $(10 \mathrm{mg} / \mathrm{L}, 100 \mathrm{mg} / \mathrm{L}$ and $1000 \mathrm{mg} / \mathrm{L}), \mathrm{GA} 3(10 \mathrm{mg} /$ $\mathrm{L}, 100 \mathrm{mg} / \mathrm{L}$ and $1000 \mathrm{mg} / \mathrm{L})$ and IAA $(50 \mathrm{mg} / \mathrm{L}, 100 \mathrm{mg} /$ $\mathrm{L}$ and $200 \mathrm{mg} / \mathrm{L}$ ). The treatment with distilled water was taken as control (Ctrl) and 100 oil palm seeds were used in each treatment. Germination rates were recorded up to 20 days after phytohormone treatment until no more germinated seeds. The seed germination rate of each treatment was calculated using the following formula:

Germination rate $(\%)=$ (number of germinated seeds $/$ number of treated seeds $) \times 100$.

\section{Data analysis}

The software SAS statistical program version 9.4 was used to analyze the data. Data in the figures were expressed as the means of all replicates \pm standard deviations. The top 10 KEGG pathways and the number of DEGs enriched in each pathway were presented by Circos software [38].

\section{Additional files}

Additional file 1: Figure S1. Quality assessment of reads. (DOCX 498 $\mathrm{kb})$

Additional file 2: Table S1. Summary of reads mapped to reference genome. (XLS $25 \mathrm{~kb}$ )

Additional file 3: Table S2. The quantification of gene expression. (XLSX 4617 kb)

Additional file 4: Table S3. Correlation analysis between replicates. (XLSX $11 \mathrm{~kb}$ )

Additional file 5: Table S4. Analysis of differentially expressed genes (DEGs). (XLSX $2492 \mathrm{~kb}$ ) 
Additional file 6: Table S5. A list of some differentially expressed genes (DEGs) with log2Ratio $\geq 10$. (XLSX $45 \mathrm{~kb}$ )

Additional file 7: Table S6. Total identified proteins of three biological replicates. (XLS $12639 \mathrm{~kb}$ )

Additional file 8: Figure S2. Venn diagram of identified proteins in three biological replicates. (DOCX $181 \mathrm{~kb}$ )

Additional file 9: Table S7. Analysis of differentially expressed proteins (DEPs). (XLS 376 kb)

Additional file 10: Figure S3. Top $10 \mathrm{KEGG}$ pathway enrichment of DEGs. Red ribbons indicate the links between 0d-Vs-70d and top 10 pathways while orange ribbons indicate the link between $0 \mathrm{~d}-\mathrm{Vs}-75 \mathrm{~d}$ and top 10 pathways. The number of DEGs in each pathway was represented by the thickness of the ribbons. (DOCX $429 \mathrm{~kb}$ )

Additional file 11: Table S8. Differentially expressed genes (DEGs) in Plant hormone signal transduction pathway. (XLSX $21 \mathrm{~kb}$ )

Additional file 12: Figure S4 Top 10 enriched GO categories of differential proteins in (A) 0d-Vs-70d (B) 0d-Vs-75d as compared with all identified proteins. (DOCX $102 \mathrm{~kb}$ )

Additional file 13: Table S9. GO classification analysis of DEPs as compared with all identified proteins. (XLSX $103 \mathrm{~kb})$

\section{Abbreviations}

ABA: abscisic acid; Aux: auxin; BR: brassinosteroid; cDNA: complementary DNA; CTK: cytokinin; Ctrl: control; DEGs: differentially expressed genes; DEPs: differentially expressed proteins; ET: ethylene; FDR: false discovery rate; FPKM: fragments per kilobase of transcripts per million mapped; GA: gibberellin; GO: Gene Ontology; IAA: Indole-3-acetic acid; JA: jasmonic acid; KGGG: Kyoto encyclopedia of genes and genomes; MRM: multiple reaction monitoring (MRM); SA: Salicylic acid

\section{Acknowledgements}

We are very grateful to the Scientific Observation and Experiment Station of Tropical oil crops, Ministry of Agriculture and Rural Affairs of China for providing oil palm seeds.

\section{Authors' contributions}

YW designed and supervised the experiments. YW and YMH performed data analysis and wrote the manuscript. YMH and $J \mathrm{~L}$ carried out RNA extraction and QPCR analysis. PS, DZ and ZZ prepared samples and carried out heat treatment. LOI designed primers for $\mathrm{PPCR}$ and revised the manuscript. All the authors read and approved the final manuscript.

\section{Funding}

This work was funded by National Natural Science Foundation of China (NSFC) (No. 31201278) and also supported by Central Public-interest Scientific Institution Basal Research Fund for Chinese Academy of Tropical Agricultural Sciences (No. 17CXTD-13). The funding agencies played no roles in the design of the study, collection, analysis, interpretation of data, and in writing the manuscript.

\section{Availability of data and materials}

RNA-seq data used in the present study have been deposited into the NCB Sequence Read Archive (SRA, https://www.ncbi.nlm.nih.gov/sra/) under the accession number of PRJNA553301 (SRR9656589, SRR9656590, SRR9656591, SRR9656592, SRR9656598, SRR9656597, SRR9656595, SRR9656596 and SRR9656587), in which T0 means 0d; SP1 means 70d and SP2 means 75d. The descriptions of biosamples used in the present study can be found in NCBI BioSample database (BioSample, https://www.ncbi.nlm.nih.gov/ biosample) under the accession numbers 12233559, 12233560, 12233561, $12233562,12233563,12233564,12233565,12233566$ and 12233567 . All the supporting data are included as additional files.

Ethics approval and consent to participate Not applicable.

\section{Consent for publication}

Not applicable.

\section{Competing interests}

The authors declare that they have no competing interests.

\section{Author details}

${ }^{1}$ Hainan Key Laboratory of Tropical Oil Crops Biology, Coconut Research Institute, Chinese Academy of Tropical Agricultural Sciences, Wenchang 571339, People's Republic of China. ${ }^{2}$ Biotechnology Research Department, Ministry of Education, Kyaukse 100301, Myanmar. ${ }^{3}$ Nigerian Institute for Oil Palm Research (NIFOR), Benin, Nigeria.

Received: 10 April 2019 Accepted: 13 August 2019

Published online: 19 August 2019

\section{References}

1. Adam H, Collin M, Richaud F, Beulé T, Cros D, Omoré A, Nodichao L, Nouy B, Tregear JW. Environmental regulation of sex determination in oil palm: current knowledge and insights from other species. Ann Bot. 2011;108:1529-37.

2. Singh R, Ong-Abdullah M, Low ETL, Manaf MAA, Rosli R, Nookiah R, Ooi LCL, Ooi SE, Chan KL, Halim MA, et al. Oil palm genome sequence reveals divergence of interfertile species in old and new worlds. Nature. 2013; 0: 335-339.

3. Bakoumé C, Wickneswari R, Rajanaidu N, Kushairi A, Amblard P, Billotte N. Allelic diversity of natural oil palm (Elaeis guineensis Jacq.) populations detected by microsatellite markers: implications for conservation. Plant Genet Resour. 2007:5:104-7.

4. Akbari G, Sanavy S, Yousefzadeh S. Effect of auxin and salt stress $(\mathrm{NaCl})$ on seed germination of wheat cultivars (Triticum sestivum L.). Pak J Biol Sci. 2007;10:2557-61.

5. Liu X, Zhang H, Zhao Y, Feng Z, Li Q, Yang H-Q, Luan S, Li J, He Z-H. Auxin controls seed dormancy through stimulation of abscisic acid signaling by inducing ARF-mediated ABI3 activation in Arabidopsis. Proc Natl Acad Sci. 2013;110:15485-90.

6. Martine BM, Hilaire KT, Mongomaké K, Roger KK, Kouakou EK, Justin KY. Effect of the hydrogen peroxide treatments on germination of oil palm (Elaeis guineensis Jacq.) seeds. Int J Agr Food Sci. 2011;1:58-65.

7. Martine BM, Laurent KK, Pierre BJ, Eugène KK, Hilaire KT, Justin KY. Effect of storage and heat treatments on the germination of oil palm (Elaeis guineensis Jacq.) seed. Afr J Agric Res. 2009;4(10):931-7.

8. Corley RHV, Tinker PB. The oil palm. $5^{\text {th }}$ edn. Wiley Blackwell; 2016. p 229-231.

9. Fondom NY, Etta CE, Mih AM. Breaking seed dormancy : revisiting heattreatment duration on germination and subsequent seedling growth of oil palm (Elaeis guineensis Jacq.) progenies. J Agric Sci. 2010;2:101-10.

10. Green M, Lima WAA, Figueiredo AF, De Atroch AL, Lopes R, Da Cunha RNV, Teixeira PC. Heat-treatment and germination of oil palm seeds (Elaeis guineensis Jacq.). J Seed Sci. 2013; I 35: 296-301.

11. Sharma A, Jain N. Plant growth hormones - the key players in the process of seed germination. Int J Res Appl Sci Eng Technol. 2016;4:334-8.

12. Chiwocha SDS, Cutler AJ, Abrams SR, Ambrose SJ, Yang J, Ross ARS, Kermode AR. The etr1-2 mutation in Arabidopsis thaliana affects the abscisic acid, auxin, cytokinin and gibberellin metabolic pathways during maintenance of seed dormancy, moist-chilling and germination. Plant J. 2005;42:35-48.

13. Kucera B, Cohn MA, Leubner-metzger G. Plant hormone interactions during seed dormancy release and germination. Seed Sci Res. 2005;15:281-307.

14. Shu K, Liu XD, Xie Q, He ZH. Two faces of one seed: hormonal regulation of dormancy and germination. Mol Plant. 2016:9:34-45.

15. Chen S-Y, Kuo S-R, Chien C-T. Roles of gibberellins and abscisic acid in dormancy and germination of red bayberry (Myrica rubra) seeds. Tree Physiol. 2008;28:1431-9.

16. Chauhan JS, Tomar YK, Singh NI, Ali S, Debarati. Effect of growth hormones on seed germination and seedling growth of black gram and horse gram. J Am Sci. 2009;5:79-84.

17. Miransari M, Smith DL. Plant hormones and seed germination. Environ Exp Bot. 2014;99:110-21

18. Guevara E, Herrera J, Alizaga R, Bangerth F. Changes in hormone concentrations during dormancy release of oil palm (Elaeis guineensis) seeds. Seed Sci Technol. 2008:36:575-87.

19. Xia W, Mason AS, Xiao Y, Liu Z, Yang Y, Lei X, Wu X, Ma Z, Peng M. Analysis of multiple transcriptomes of the African oil palm (Elaeis quineensis) to identify reference genes for RT-qPCR. J Biotechnol. 2014;184:63-73. 
20. Kumar D, Bansal G, Narang A, Basak T, Abbas T, Dash D. Integrating transcriptome and proteome profiling: strategies and applications. Proteomics. 2016;16:2533-44.

21. Wu J, Xu Z, Zhang Y, Chai L, Yi H, Deng X. An integrative analysis of the transcriptome and proteome of the pulp of a spontaneous late-ripening sweet orange mutant and its wild type improves our understanding of fruit ripening in citrus. J Exp Bot. 2014;65:1651-71.

22. Peng $X$, Qin Z, Zhang G, Guo Y, Huang J. Integration of the proteome and transcriptome reveals multiple levels of gene regulation in the rice $\mathrm{dl} 2$ mutant. Front Plant Sci. 2015;6:351.

23. Nambara E, Okamoto M, Tatematsu K, Yano R, Seo M, Kamiya Y. Abscisic acid and the control of seed dormancy and germination. Seed Sci Res. 2010;20:55-67.

24. Zhu Y, Zhu G, Guo Q, Zhu Z, Wang C, Liu Z. A comparative proteomic analysis of Pinellia ternata leaves exposed to heat stress. Int J Mol Sci. 2013;14:20614-34.

25. Ng LM, Melcher K, Teh BT, Eric XH. Abscisic acid perception and signaling: structural mechanisms and applications. Acta Pharmacol Sin. 2014;35(5):567-84

26. Sah SK, Reddy KR, Li J. Abscisic acid and abiotic atress tolerance in crop plants. Front Plant Sci. 2016;7:1-26.

27. White CN, Rivin CJ. Gibberellins and seed development in maize. II. Gibberellin synthesis inhibition enhances abscisic acid signaling in cultured embryos. Plant Physiol. 2000;122:1089-97.

28. Graeber KAl, Nakabayashi K, Miatton E, Leubner-metzger G, Soppe WIMJJ. Molecular mechanisms of seed dormancy. Plant Cell Environ. 2012;35:1769-86.

29. Wang Y, Li L, Ye T, Zhao S, Liu Z, Feng YQ, Wu Y. Cytokinin antagonizes ABA suppression to seed germination of Arabidopsis by downregulating ABI5 expression. Plant J. 2011;68:249-61.

30. Riefler M, Novak O, Strnad M, Schmülling T. Arabidopsis cytokinin receptor mutants reveal functions in shoot growth, leaf senescence, seed size, germination, root development, and cytokinin metabolism Plant Cell. 2006;18:40-54.

31. Begcy K, Sandhu J, Walia H. Transient heat stress during early seed development primes germination and seedling establishment in rice. Front Plant Sci. 2018:9:1768.

32. Ramaih S, Guedira M, Paulsen G. Relationship of indoleacetic acid and tryptophan to dormancy and preharvest sprouting of wheat. Funct Plant Biol. 2003;30:939-45.

33. Brady SM, Sarkar SF, Bonetta D, MCCourt P. The ABSCISIC ACID INSENSITIVE 3 ( $A B \mid 3$ ) gene is modulated by farnesylation and is involved in auxin signaling and lateral root development in Arabidopsis. Plant J. 2003;34:67-75.

34. Liu P, Montgomery TA, Fahlgren N, Kasschau KD, Nonogaki H, Carrington JC. Repression of AUXIN RESPONSE FACTOR10 by microRNA160 is critical for seed germination and post-germination stages. Plant J. 2007;52:133-46.

35. Li H, Durbin R. Fast and accurate short read alignment with burrowswheeler transform. Bioinformatics. 2009;25(14):1754-60.

36. Li B, Dewey CN. RSEM: accurate transcript quantification from RNA-Seq data with or without a reference genome. BMC Bioinformatics. 2011:12:323.

37. Tarazona S, García-Alcalde F, Dopazo J, Ferrer A, Conesa A. Differential expression in RNA-seq: a matter of depth. Genome Res. 2011:21(12):2213-23.

38. Krzywinski M, Schein J, Birol I, Connors J, Gascoyne R, Horsman D, Jones SJ, Marra MA. Circos: an information aesthetic for comparative genomics. Genome Res. 2009;19:1639-45.

\section{Publisher's Note}

Springer Nature remains neutral with regard to jurisdictional claims in published maps and institutional affiliations.

Ready to submit your research? Choose BMC and benefit from:
- fast, convenient online submission
- thorough peer review by experienced researchers in your field
- rapid publication on acceptance
- support for research data, including large and complex data types
- gold Open Access which fosters wider collaboration and increased citations
- maximum visibility for your research: over 100M website views per year
At BMC, research is always in progress.
Learn more biomedcentral.com/submissions

